\title{
COnE)-(OES
}

CIÊNCIA E TECNOLOGIA

\section{A PLURALIDADE DOS SABERES DOS DOCENTES E AS RELAÇÕES ENTRE SI: UMA ABORDAGEM SOBRE A FORMAÇÃO DOS PROFESSORES DA LICENCIATURA EM QUÍMICA NO IFCE MARACANAÚ (CE)}

\author{
Vitória Maria Coutinho Gomes, Silvany Bastos Santiago \\ Instituto Federal de Educação, Ciência e Tecnologia do Ceará - IFCE \\ <vivi_coutinhog23@hotmail.com>.<silvany.santiago@ifce.edu.br> \\ DOI: $10.21439 /$ conexoes.v15i0.2076
}

\begin{abstract}
Resumo. Este artigo traz um estudo sobre a docência universitária, especificamente do Instituto Federal de Educação Ciência e Tecnologia no Campus de Maracanaú, tradicionalmente essa instituição oferta cursos técnicos e a partir de 2008, cursos de licenciatura. O objetivo principal dessa pesquisa é compreender a pluralidade dos saberes dos professores das disciplinas específicas do curso de Licenciatura em Química. Trata-se de uma pesquisa descritiva através de um estudo de caso. Como técnica de pesquisa foi elaborado um questionário através do recurso do whatsapp, em razão da atual Pandemia e tendo em vista acatar o Decreto no 33.510/2020, de 16 de março de 2020*, do Governo do Estado do Ceará, que estabelece um momento crítico no sistema de saúde e instruiu sobre as precauções na tentativa de reduzir o contágio pelo novo Coronavírus. Os resultados mostraram que os conhecimentos e as competências exercem influência na prática e contribuem com o processo identitário de cada docente.
\end{abstract}

Palavras-chaves: Saberes docentes. Saberes Experienciais. Docência. Licenciaturas.

\section{THE PLURALITY OF THE TEACHERS' KNOWLEDGE AND THE RELATIONSHIPS BETWEEN THEM: AN APPROACH TO THE TEACHERS' TRAINING IN CHEMISTRY AT IFCE MARACANAÚ (CE)}

\begin{abstract}
This article brings a study on university teaching, specifically the Instituto Federal de Educação Ciência e Tecnologia on the Campus of Maracanaú, traditionally this institution offers technnical courses and from 2008 onwards, undergraduate course. The main objective of this research is to understand the plurality of knowledge of teachers in specific disciplines of the Licentiate Degree in Chemistry. This is a descriptive research through a case study. As a research technique, a questionnaire was prepared using whatsapp, due to the current Pandemic and with a view to complying with Decree No. 33510/2020, of March16, 2020, of the Government of the State of Ceará, which establishes a critical moment in the health system and instructed on precautions in na attempt to reduce the spread of the new Coronavirus. The results showed that knowledge and skills influence practice and contribute to the identity process of each teacher.
\end{abstract}

Keywords: Teaching knowledge. Experiential Knowledge. Teaching. Degrees.

\section{INTRODUÇÃO}

O presente trabalho traz um estudo sobre a compreensão dos saberes docentes e a sua pluralidade diante das disciplinas específicas do curso de licenciatura em Química. O cenário da pesquisa foi o Instituto Fede- ral do Ceará (IFCE), campus Maracanaú, essa instituição disponibiliza o ensino técnico, superior e pósgraduação, investe em atividades de extensão, promove o suporte nos processos educativos vinculados a independência financeira dos discentes e ofertam cursos 
A PLURALIDADE DOS SABERES DOS DOCENTES E AS RELAÇÕES ENTRE SI: UMA ABORDAGEM SOBRE A FORMAÇÃO DOS PROFESSORES DA LICENCIATURA EM QUÍMICA NO IFCE MARACANAÚ (CE)

de formação inicial e continuada visando o aperfeiçoamento da prática dos professores.

Como base da investigação destacam-se os questionamentos que nortearam este trabalho como: os professores têm ciência da temática saberes docentes? De que maneira os saberes experienciais adquiridos na prática influenciam a metodologia dos professores? Referendando-se às inquietações se oferece como objetivo geral: compreender a pluralidade dos saberes dos professores das disciplinas específicas do curso de Licenciatura em Química e objetivos específicos nos quais se incluem a identificação dos principais motivos que influenciam na escolha da docência como profissão; verificar a compreensão e a relevância acerca da temática dos saberes docentes mediante a formação acadêmica dos participantes e conhecer, a partir do ponto de vista dos docentes pesquisados, quais são as competências que eles julgam ser necessárias à docência superior no ensino de Química.

Dentre os autores que embasaram a pesquisa destacam-se Tardif (2014) que trata sobre os saberes docentes, suas características, afinidades e implicações na formação do professor e Gauthier (2013) que discorre sobre o saber experiencial dos professores através de suas pesquisas em sala de aula. Este trabalho está estruturado em três secções iniciando-se com a evolução histórica dos Institutos Federais. A secção seguinte é sobre os saberes docentes suas características, afinidades e implicações na formação do professor. Posteriormente, é explicitada a metodologia da investigação, bem como seus resultados e discussões. Por fim as considerações finais sobre a pesquisa.

\section{BREVE HISTÓRICO DOS INSTITUTOS FE- DERAIS DE EDUCAÇÃO}

Esta secção apresenta a evolução histórica dos Institutos Federais de Educação como propósito situar essa instituição como uma política educacional de profissionalização do ensino brasileiro por mais de um século.

No governo de Nilo Peçanha (1909) o aumento da população nas cidades tornou-se motivo de preocupação da classe dominante, pois os indivíduos desfavorecidos poderiam oferecer riscos, devido sua conjuntura ociosa na sociedade.

$\mathrm{Na}$ tentativa de satisfazer os desejos da burguesia e oferecer oportunidades educacionais ao proletariado, por intermédio do Decreto 7566, foram criadas 19 Escolas de Aprendizes e Artífices (EAA), as quais forneciam uma educação gratuita, de cunho profissional e com serventia tanto para o mercado de trabalho quanto para o convívio comunitário (COSTA, 2013, p. 1).

Com essa política educacional, a profissionalização no ensino brasileiro tinha o intuito de formar mão-deobra para atividades manuais, como artesanato ou ofícios leves, intensificando o processo de estratificação social.

$\mathrm{Na}$ década de 30, o Brasil sofreu muitas transformações no âmbito social, religioso e principalmente no ensino, como a fundação do Ministério da Educação e Saúde Pública que com a ajuda da Inspetoria supervisionavam os conhecimentos transmitidos para a população e a reforma no ensino secundário e superior (BOUTIN; SILVA, 2015, p. 4491).

Aos poucos, o trabalho manufaturado foi substituído pelo fabril, devido a produção em série nas fábricas. A classe operária não precisava de muita instrução, apenas exercer a mesma função durante a confecção dos produtos, assim como é dito por Saviani (2021, p. 23):

\footnotetext{
Com efeito, se no artesanato o trabalho era subjetivo, isto é, os instrumentos de trabalho eram dispostos em função do trabalhador e este dispunha deles segundo seus desígnios, na produção fabril essa relação é invertida. Aqui é o trabalhador que deve se adaptar ao processo de trabalho, já que este foi objetivado e organizado na forma parcelada. Nessas condições, o trabalhador ocupa seu posto na linha de montagem e executa determinada parcela do trabalho necessário para produzir determinados objetos. O produto é, pois, uma decorrência da forma como é organizado o processo.
}

Na década de 1930, a industrialização possibilitou grande progresso para o Brasil, pois além de ofertar muitos empregos nas fábricas para a classe dominada, promoveu mudanças no processo de aprendizagem através da transformação das EAA onde os Liceus Industriais, destinados a todos os ramos e graus. O sistema educacional, pela primeira vez, estava interligado ao de produção oferecendo ensino técnico, profissional e industrial. No ano de 1942, foi assinado o Decreto-Lei 4127, os Liceus passavam a ser substituídos por Escolas Industriais e Técnicas, que forneciam ensino equivalente ao nível secundário.

Desde o começo do século XX, a educação profissional foi uma estratégia governamental de manipular as massas, portanto, assegurava e favorecia os direitos da burguesia. No mandato de Getúlio Vargas, mesmo sendo considerado o "Pai dos Pobres", não houve mudanças no sistema (BOUTIN; SILVA, 2015, p. 4495).

A partir de 1959, com o desenvolvimento do país em larga escala, as Escolas Industriais e Técnicas foram transformadas em Escolas Técnicas Federais, atribuindo o ensino profissionalizante ao acadêmico. Com sustentação teórica no empirismo, no positivismo e influenciada pela corrente behaviorista, a pedagogia tecnicista, lentamente, surgiu no cenário brasileiro (GARCIA; CALDAS; PEREIRA, 2005). 
A PLURALIDADE DOS SABERES DOS DOCENTES E AS RELAÇÕES ENTRE SI: UMA ABORDAGEM SOBRE A FORMAÇÃO DOS PROFESSORES DA LICENCIATURA EM QUÍMICA NO IFCE MARACANAÚ (CE)

A pedagogia tecnicista, predominante na década de 1960, tinha como principal característica formar indivíduos para o mercado de trabalho por meio do aprendizado efetivo e técnico oferecidos pelas escolas da época, chamadas de Escolas Técnicas Federais (ETFs). Porém, essa abordagem não valorizava os grupos presentes no processo ensino-aprendizagem, pois o objeto prioritário é a organização racional dos meios, na qual o ensino não se centrava no professor e nem no aluno, mas nos objetivos e nas técnicas de ensino que garantem o alcance deles (OLIVEIRA et al. 2017).

Durante esse período, o ensino era voltado para a produção de mão-de-obra em fábricas, pois o nosso país precisava com urgência da formação profissionalizante para aumentar o nível de desenvolvimento tecnológico da nação.

Segundo Libâneo (1989, p. 290 apud SILVA, 2018, p. 100),

\footnotetext{
a educação atua no aperfeiçoamento da ordem social vigente, articulando-se diretamente com o sistema produtivo; para tanto emprega a ciência da mudança de comportamento, ou seja, a tecnologia comportamental. Seu interesse imediato é o de produzir indivíduos competentes para o mercado de trabalho, transmitindo, eficientemente, informações precisas, objetivas e rápidas.
}

Assim, a nova ordem econômica mundial exigia que o aprendizado fosse totalmente voltado para a tecnologia. Com isso, as ETFs mudaram a nomenclatura para Centros Federais de Educação Tecnológica (Cefets), através da Lei ${ }^{\circ} 6545$, no dia 30 de junho de 1978. Os Cefets são instituições de regime especial, de natureza pluricurricular e multiunidade (unidade sede e unidades de ensino descentralizada) que disponibilizavam o ensino técnico através de cursos, o ensino superior graduado (licenciatura, tecnologia e bacharelado) e o ensino superior pós-graduado (especialização, mestrado e doutorado). Esses centros tinham o objetivo de qualificar os indivíduos para o mercado de trabalho, além de permitir a produção de pesquisas e desenvolver projetos a partir dos seus resultados.

No ano de 2008, os Centros Tecnológicos (Cefets) foram substituídos pelos Institutos Federais de Educação, Ciência e Tecnologia, por intermédio da Lei $\mathrm{n}^{\circ}$ 11892, em 29 de dezembro. Esse preceito determinava a fundação de trinta e oito Institutos Federais (IF's) com o intuito de aprimorar o ensino e desenvolver o âmbito econômico atrelado ao social. A Rede Federal concede educação gratuita em todos os níveis, desde profissional tecnológica à pós-graduação e por meio de projetos de extensão desenvolvidos com a comunidade contribuem para o incentivo à pesquisa gerando impacto na sociedade a fim de melhorar o cenário vigente com soluções técnicas e tecnológicas.
O Instituto Federal do Ceará, Campus de Maracanaú, está situado próximo ao Centro Industrial. Esse polo universitário possui o compromisso de suprir a procura de profissionais capacitados pelas indústrias do município, visto que qualifica os estudantes e auxilia na sua inserção no setor industrial.

O Campus de Maracanaú oferece programas de pesquisa de iniciação científica, como é o caso do Programa Institucional de Bolsas de Iniciação Científica (PIBIC) e Programa Institucional de Bolsas de Iniciação em desenvolvimento Tecnológico e Inovação (PIBIT) que disponibilizam bolsas para o aluno instigando o desenvolvimento do conhecimento científico e o Programa de Apoio à Produtividade em Pesquisa (PROAPP) que estimula os professores, servidores ou técnicos a difundirem seus saberes. Existem programas também que fomentam eventos realizados pela comunidade tecnológica através do custeio de despesas essenciais dos mestres e dos graduandos.

Ademais, integra projetos de extensão social mediante a convênios e ao governo permitindo a participação da comunidade estudantil, docente e local nas tarefas educacionais e a proximidade dos alunos com o ambiente industrial a fim de viabilizar sua inclusão no mercado de trabalho e propicia aos funcionários da instituição a aplicação de formação inicial e continuada, buscando atualizar e aperfeiçoar os profissionais no campo pedagógico.

Neste espaço de tempo, os novos estudos produziram um amplo conceito que fosse além da vida acadêmica, incluindo o crescimento pessoal e profissional, baseando-se nas experiências de vida de cada docente. É a partir dessa perspectiva, no campo acadêmico, que os saberes gerados pelos mestres passaram a ser incorporados na esfera educacional.

\section{SABERES DOCENTES: CARACTERÍSTI- CAS, AFINIDADES E IMPLICAÇÕES NA FORMAÇÃO DO PROFESSOR}

Os saberes docentes são ferramentas que os professores ao longo da carreira profissional vão agregando a sua prática, integrados no currículo através de cursos ofertados, formação inicial ou produzidos por meio das experiências dentro de sala de aula.

\footnotetext{
É impossível compreender a natureza do saber dos professores sem colocá-lo em íntima relação com o que os professores, nos espaços de trabalho cotidiano, são, fazem, pensam, dizem. O saber dos professores é profundamente social e é, ao mesmo tempo, o saber dos atores individuais que o possuem e o incorporam à sua prática profissional para a ela adaptá-lo e para transformá-lo (TARDIF, 2014).
} 
A PLURALIDADE DOS SABERES DOS DOCENTES E AS RELAÇÕES ENTRE SI: UMA ABORDAGEM SOBRE A FORMAÇÃO DOS PROFESSORES DA LICENCIATURA EM QUÍMICA NO IFCE MARACANAÚ (CE)

De fato, essas competências, habilidades e conhecimentos adquiridos nessas fases são significativas para o entendimento de decisões tomadas pelo indivíduo, uma vez que os resquícios das experiências domésticas, colegiais e acadêmicas estão interligados por meio de referenciais emotivos ou geográficos que auxiliam na memorização e na própria formação.

Em suma, o professor ideal é alguém que deve conhecer sua matéria, sua disciplina e seu programa, além de possuir certos conhecimentos relativos às ciências da educação $\mathrm{e}$ a pedagogia e desenvolver um saber prático baseado em sua experiência cotidiana com os alunos (TARDIF, 2014, p. 39).

O exercício da profissão possibilita aos professores desenvolverem habilidades pessoais, como é o caso do improviso e da interatividade com os alunos na sala de aula. Logo, cabe ao docente perceber a evolução de cada discente, assim como as dificuldades enfrentadas tanto pelos estudantes como pela instituição escolar, permitindo o crescimento do Habitus, manifestado através de traços pessoais do docente, como o saber-fazer e o saber-ser.

Esses saberes contribuem para a desenvoltura do professor dentro da escola e são baseados em três condições que compõem sua práxis: as relações interpessoais desenvolvidas no âmbito escolar, as atribuições e as regras impostas pelo trabalho e pelo estabelecimento de ensino, juntamente com suas finalidades múltiplas. Os conhecimentos práticos possuem uma certa objetividade, pois os preceptores transmitem suas experiências ao longo do cotidiano, o que faz deles além de instrumentos práticos, também formadores.

Todavia, Tardif (2014) atribui um interesse característico na formação docente pelos saberes práticos em referência aos outros saberes, explicando que existe uma relação de exterioridade para com os saberes curriculares, disciplinares e de formação profissional. Entretanto, os conhecimentos práticos são mais valorizados pelos professores, pois pode ser controlada a produção e veiculação desses saberes.

Portanto, os docentes determinam um papel fundamental na partilha de seus saberes com outros, pois compartilham os seus traços de personalidade utilizados em classe, através das técnicas desenvolvidas por cada professor e do material aplicado com os discentes. Ademais, as experiências vividas por cada preceptor são responsáveis pela troca de informações e pelo bom convívio social entre os envolvidos. Nesse pensamento, os saberes docentes são mediadores indispensáveis que integram a práxis do educador, advindos de diferentes lugares por meio da sua vida pessoal, préprofissional e profissional.

\section{METODOLOGIA}

O presente trabalho é de abordagem qualitativa em forma de pesquisa descritiva, pois, analisa subjetivamente as características de determinada população buscando compreender a pluralidade dos saberes dos professores das disciplinas específicas do curso de Licenciatura em Química do IFCE - Campus Maracanaú.

Na percepção de Lüdke e André (2013), a abordagem qualitativa caracteriza-se em um ambiente natural contendo, predominantemente, informações descritivas que evidenciam a realidade complexa a partir da perspectiva dos participantes.

Segundo Gil (2019), as pesquisas descritivas também chamadas de sociais, possuem o intuito de levantar as opiniões, atitudes e crenças de indivíduos ou um fato observado ou a determinação de afinidades entre as variáveis.

Através de um questionário, procurou-se analisar o perfil dos profissionais, juntamente com as dificuldades desenvolvidas e as possíveis soluções apresentadas para os problemas cotidianos enfrentados pelo professorado.

\subsection{Sujeitos da Pesquisa}

Foram quatro professores que ministram disciplinas específicas na graduação de Licenciatura em Química no Campus Maracanaú como: Química Geral I; História da Química; Química Analítica I, II, III; FísicoQuímica I,II,III; Química Orgânica I,II,III; Bioquímica; Didática de Ensino de Química e Química de Produtos Naturais. Essa seleção foi realizada por meio do contato prévio com a grade docente anexada ao projeto pedagógico do curso.

\subsection{Delineamento e Técnica de Pesquisa para Co- leta de Dados}

A pesquisa delineada como descritiva e procurou compreender a pluralidade dos saberes dos professores das cadeiras específicas do curso de Licenciatura em Química no IFCE - Campus Maracanaú a partir de "valores, crenças, hábitos, atitudes, representações, opiniões e adéqua-se a aprofundar a complexidade de fatos e processos particulares e específicos a indivíduos e grupos" (PAULILO, 1999, p. 135).

A princípio, a intenção era entrevistar presencialmente todos os docentes que lecionam as disciplinas específicas no curso de Licenciatura em Química, mas devido a situação atual da Pandemia e visando cumprir o Decreto n ${ }^{\mathrm{o}}$ 33510/2020, de 16 de março de 2020, 
A PLURALIDADE DOS SABERES DOS DOCENTES E AS RELAÇÕES ENTRE SI: UMA ABORDAGEM SOBRE A FORMAÇÃO DOS PROFESSORES DA LICENCIATURA EM QUÍMICA NO IFCE MARACANAÚ (CE)

do Governo do Estado do Ceará, que determina emergência em saúde e orienta sobre medidas preventivas para tentar controlar a infecção pelo novo Coronavírus (COVID-19) na humanidade, a pesquisa teve que modificar o procedimento utilizado para a coleta de dados.

Desse modo, pensando na melhor opção para prevenir e salvaguardar a integridade física dos envolvidos, optou-se pelo questionário online via WhatsApp para ser aplicado aos professores.

A pesquisa obteve contribuição voluntária de 4 professores que lecionam disciplinas específicas do curso de Licenciatura em Química no Campus Maracanaú. Em virtude da proteção e da discrição dos formadores contribuintes, cada docente foi representado pela junção da letra "P" acompanhado de um algarismo de 1 a 4. Os números expressaram a distinção entre eles, desse modo são ilustrados como P1,P2,P3 e P4 no capítulo seguinte.

A coleta de dados sucedeu entre dezembro de 2020 a fevereiro de 2021 com perguntas enviadas via What$s A p p$ abrangendo a formação acadêmica, o tempo de magistério, a escolha da profissão, ao nível de conhecimento dos professores sobre os saberes docentes, a importância dos conhecimentos pedagógicos para a docência, as competências e as dificuldades em relação ao magistério superior.

\section{ANÁLISES E DISCUSSÕES DOS RESULTA- DOS}

Os resultados a seguir foram discutidos a partir da análise das respostas obtidas no questionário via WhatsApp empregado aos docentes das específicas do curso de Licenciatura em Química no IFCE - Campus Maracanaú. Essa parte da pesquisa foi estruturada em quatro tópicos: Perfil dos Professores, Predileção pela Docência, Experiência Profissional e Autoavaliação.

\subsection{Perfil dos Professores}

A grade do curso de Licenciatura em Química no Campus Maracanaú é constituída por 6 professores responsáveis pelas disciplinas específicas, mas somente 4 participaram dessa pesquisa, dos quais 3 são do gênero feminino e 1 do gênero masculino. A experiência profissional dos participantes no IFCE - Campus Maracanaú corresponde em sua maioria 11 anos. Os 4 professores da pesquisa ocupam-se com 40 horas semanais em sistema de dedicação exclusiva. No que diz respeito a qualificação profissional e aos títulos universitários, o grupo é constituído por 1 Licenciado em Química/Doutorado, 1 Bacharel em Farmácia/Doutorado, 1 Bacharel em Química Industrial/Doutorado e 1 Li- cenciado em Química/Bacharel em Química Industrial/Mestrado.

\subsection{Predileção pela docência em Química como carreira profissional}

O conjunto examinado compartilha a mesma escolha de profissão ao optar pela docência em Química. Portanto, deduz-se que o pensamento de alguns indivíduos foi modificado em um certo período, visto que, temos o bacharelado como formação acadêmica inicial dentre os resultados. Ao longo do questionário permitiu descobrir o que mais incentivou a cada um dos docentes na preferência ao Ensino como ocupação profissional a partir de perguntas pessoais que almejam respostas objetivas e subjetivas, tais como:

O gráfico da Figura 1 apresenta os principais motivos que influenciaram a entrada dos professores no magistério. A princípio, a identificação com a docência é o estímulo mais citado pelos participantes da pesquisa. Essa informação é pertinente ao estudo, pois, o ingresso no professorado pela satisfação impulsiona a dinâmica do ensino, beneficia o indivíduo juntamente com a sua formação. Em seguida, P3 citou a estabilidade financeira como grande motivação para seguir carreira profissional no Ensino Superior.

A predileção pela docência também pode ser instigada por meio de acontecimentos que marcaram a vida do sujeito, de maneira favorável ou desfavorável. Desse modo, os professores relataram fatos que somente favoreceram seus caminhos e sua decisão pela profissão, conforme ditos em P1, P3 e P4:

“(...) Nunca houve com meus amigos e minha família qualquer crítica às minhas decisões na escolha de ser professora. A minha família sempre apoiou as minhas escolhas. Quando decidi seguir a carreira docente todos ficaram felizes e orgulhosos com a minha conquista. (...)" - P1

“(...) Positivamente, pois minha professora da alfabetização tia Edméia era muito dedicada e a professora Iris do 4 ano do fundamental era muito engajada. (...)”- P3

“(...) Minha maior referência foi um professor da disciplina de Físico-Química que me inspirou muito. Atualmente é uma das disciplinas que ministro. (...)” -

O docente P1 considera essencial o apoio da família e dos amigos no momento da escolha pela carreira. Já P3 e P4, a inspiração para lecionar veio por intermédio de um bom professor durante a infância ou no decorrer 


\section{MOTIVOS DE INGRESSO NA DOCENCIA}

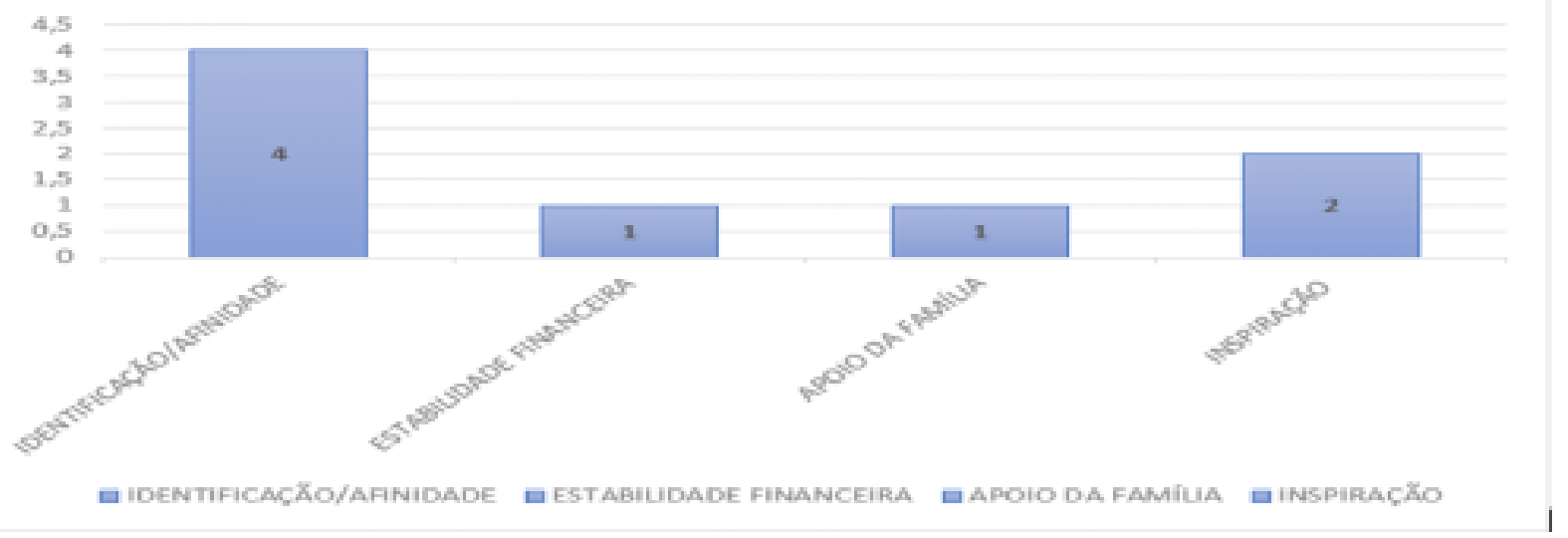

da juventude. Para terminar, P2 não forneceu respostas nessa questão e, portanto, não contribuiu nesse quesito para a pesquisa.

\subsection{Experiência profissional}

Nesse tópico, de acordo com a qualificação profissional de cada professor, verificou-se o grau de conhecimento e de relevância dos saberes docentes a partir das seguintes perguntas:

Quanto à temática dos saberes é compreendida por todos os professores, tanto pelos licenciados quanto pelos bacharéis. No entanto, ao comparar P1 e P2, é notável que P1 entende melhor, uma vez que o assunto já foi lido e estudado em alguns momentos durante a sua docência. Enquanto P2 até compreende, mas não sabe o que significa de fato a expressão. Percebe-se pelos depoimentos dos professores:

“(...) A temática já foi lida e estudada em alguns momentos durante a minha ação como professora.

$$
\text { (...)" - Pl }
$$

“(...) Compreendo. Só não sei se é o que de fato a expressão significa. (...)”- $P 2$

Ao verificar as respostas de P3 e P4, percebemos que as respostas são complementares, devido P3 citar os saberes profissionais adquiridos através das formações e P4 mencionar as experiências conquistadas tanto na prática quanto fora dela.

“(...) Entendo como se fossem os conhecimentos necessários para um bom desenvimento da atividade docente. Como por exemplo, os saberes pedagógicos, os saberes da área de conhecimento do qual o docente leciona. (...)”- P3
“(...) Acredito que seja um saber oriundo não somente da formação, de caráter heterogêneo, que perpassa pelo conhecimento adquirido pela vivência no ambiente profissional e fora dele. (...)”- P4

Em relação a necessidade dos saberes para a docência, as justificativas demonstram o ponto de vista dos professores nesse quesito e encontram-se explanadas a seguir:

“(...) Os conhecimentos pedagógicos são importantes para a ação do profissional, muitos desses conhecimentos nos permite buscar estratégias de ensino que nos faz aproximar o aluno ao conteúdo a ser abordado. Claro que, a depender do aluno, dever-se-á buscar estratégias diferentes. Para isso, é importante conhecer e compreender a realidade do universo no qual esses alunos podem estar inseridos.

$$
\text { (...) })-P 1
$$

“(...) Não acho necessário, mas importantes para compreender o todo numa relação ensino-aprendizagem ou docente-discente. (...)” - P2

“(...) Sim. Dependendo da instituição, vejo que a parte pedagógica é muitas vezes colocada como irrelevante, no entanto eu compreendo tais saberes como uma necessidade que de fato se bem aprendida, desenvolvida facilita a aquisição do conhecimento, da aprendizagem por parte dos alunos. (...)” - P3

“(...) Sim. O conhecimento específico de uma determinada disciplina para ser transmitido eficientemente necessita das ferramentas pedagógicas que auxiliarão na prática docente. (...)” - P4 
A PLURALIDADE DOS SABERES DOS DOCENTES E AS RELAÇÕES ENTRE SI: UMA ABORDAGEM SOBRE A FORMAÇÃO DOS PROFESSORES DA LICENCIATURA EM QUÍMICA NO IFCE MARACANAÚ (CE)

Percebe-se a partir das respostas que o grupo foi dividido em dois posicionamentos, no qual P1, P3 e P4 concordam entre si sobre a necessidade dos saberes pedagógicos para a prática docente e $\mathrm{P} 2$ possui opinião contraditória aos demais professores. Ainda conforme os resultados acima, podemos inferir que os professores consideram os saberes docentes importantes para a prática docente, pois além de auxiliar na busca de estratégias permitindo facilitar o aprendizado dos discentes, influencia na metodologia utilizada dentro da classe.

Com base nessa última informação, as menções abaixo demonstram a percepção e de que modo ocorre a influência dos saberes práticos no método adotado dentro de sala de aula.

“(...) Influenciam sim. Fatores como ética, competência profissional, saber dialogar com os alunos, buscar sempre uma relação entre a liberdade em sala sem perder o respeito da turma, entre outros saberes, são de extrema importância para a aplicação de metodologias de ensino no ambiente de sala de aula. (...)”-PI

“(...) Sim, influenciam. É justamente devido à experiência que vamos adquirindo com o tempo que podemos propor novas metodologias. Nesse aspecto, também é relevante considerar que somado ao fator tempo, cada turma é única e diferente da outra, então, a cada semestre, tenho que adaptar o que tenho ao novo. (...)”- $P 2$

“(...) Sim. A vivência é muito importante na formação docente, no melhoramento da sua prática docente.

Com a prática, vamos aprendendo a adequar as práticas pedagógicas que melhor se adequam para cada conteúdo, perfil do aluno, modalidade de ensino presencial ou a distância etc. (...)” - P3

“(...) Sim. Porque a metodologia utilizada pelo professor geralmente é a que ele sente maior segurança. Isto está associado aos seus saberes docentes. (...)" - P4

Os docentes pesquisados deram retornos positivos sobre os saberes experienciais interferirem na metodologia do professor no ambiente acadêmico. As menções acima revelam que a partir da combinação das experiências vividas juntamente com as competências profissionais é possível intervir no método aplicado em sala de aula.

Essa informação é significativa para a pesquisa, pois, saberes práticos colaboram na otimização do desempenho do professor na escola através do desenvolvimento de suas habilidades, proporcionando o aumento do ensino docente personalizado.
Dessa forma, as respostas do grupo analisado para as competências necessárias durante o exercício do magistério superior em Química estão organizadas na Tabela 1 .

Conforme a opinião dos professores, as competências profissionais são desenvolvidas através da vivência em sala de aula com a finalidade de facilitar o aprendizado dos discentes. Na Tabela 1 é possível compreender que as respostas estão em sincronia, independente da formação acadêmica inicial do corpo docente.

O grupo concilia as opiniões nesse quesito, em virtude de $\mathrm{P} 3$ resumir as competências que foram explanadas por P1, P2 e P4. O docente P3 cita o conhecimento técnico e os saberes docentes como os principais recursos para a execução eficiente do professorado superior em Química, enquanto que P1, P2 e P4 detalham a resposta de P3 em quatro capacidades mais recorrentes na prática, como o conhecimento sobre a matéria, interação efetiva com os discentes, organização e facilitar o aprendizado através da contextualização do conteúdo. Nessa sequência e diante dessas competências fizemos uma autoavaliação com cada docente, discutindo as dificuldades e as soluções no exercício docente superior de Química.

\subsection{Autoavaliação, dificuldades e soluções no exercício docente}

Neste tópico permitiu uma reflexão sobre a prática aplicada, além de discutir os principais problemas enfrentados pelos professores e as possíveis soluções durante o exercício docente. Os gráficos a seguir representam os dados fornecidos a partir de quatro perguntas:

"Você consegue repassar seus conhecimentos de Química com clareza? Como sua disciplina de Química é ministrada? Quais são as suas dificuldades no exercício da docência? Como faz para superá-las?"

Apoiado em observações, a metade dos professores dispõe o mesmo pensamento, exceto P3 e P4. É perceptível uma certa insegurança por parte de P1 e P2 quanto ao repasse dos conteúdos ministrados, em contrapartida P3 e P4 afirmam que transmite de maneira clara os assuntos, uns com mais facilidade do que outros a partir das seguintes respostas:

“(...) Espero que consiga passar com clareza os conteúdos de química que ministro. (...)” - P1

“(...) A percepção que tenho sobre o desenvolvimento dos estudantes à medida que o conhecimento é passado de mim para eles, sempre há uma parte da turma que me mostra que sim, que consigo repassar os conhecimentos, mas também a parte na qual não consigo êxito. (...)” - P2 
A PLURALIDADE DOS SABERES DOS DOCENTES E AS RELAÇÕES ENTRE SI: UMA ABORDAGEM SOBRE A FORMAÇÃO DOS PROFESSORES DA LICENCIATURA EM QUÍMICA NO IFCE MARACANAÚ (CE)

Tabela 1: COMPETÊNCIAS NECESSÁRIAS PARA O MAGISTÉRIO SUPERIOR - QUÍMICA

\begin{tabular}{|c|l|}
\hline DOCENTES & \multicolumn{1}{c|}{ COMPETENCIAS } \\
\hline P1 & $\begin{array}{l}\text { Competências de área, conhecimento do universo do aluno, novas estratégias } \\
\text { de metodologia de ensino e contextualizar o conteúdo de química com a } \\
\text { realidade dos alunos. }\end{array}$ \\
\hline P2 & $\begin{array}{l}\text { Conhecimento sobre a matéria, boa relação docente-discente, organização e } \\
\text { responsabilidade. }\end{array}$ \\
\hline P3 & Conhecimento técnico e saberes docentes. \\
\hline P4 & $\begin{array}{l}\text { Conhecimento sobre a matéria, planejamento do conteúdo das aulas, facilitar } \\
\text { o entendimento, interação com os discentes, avaliar e orientar. }\end{array}$ \\
\hline
\end{tabular}

“(...) Acredito que geralmente sim. As vezes tenho dificuldade em certos conteúdos que talvez a prática pedagógica poderia ajudar. Mas penso que existem também outros fatores, tais como: limitações estruturais (laboratórios inapropriados), carga horária, etc. (...)”-P3

“(...) Sim, alguns conteúdos com mais facilidade! (...) $)-P 4$

A segunda pergunta refere-se a como o Ensino de Química é ministrado na Instituição pelos professores, obtivemos respostas dos participantes $\mathrm{P} 1, \mathrm{P} 3$ e P4, uma vez que P2 não respondeu a questão e portanto não contribuiu nesse quesito para a pesquisa.

“(...) Depende da disciplina, alguns assuntos da química exigem que o professor trabalhe um pouco mais com aulas expositivas, utilização do quadro (no caso remoto tenho feito uso da lousa digitalizadora) $e$

resolução de exercícios, isso ocorre muito com a

Química Analítica I, II e III. Para algumas outras disciplinas é possível fazer uso de slides, realizar estudo de textos, seminários, aprendizagem baseada em problemas, estudo de caso. (...)” - PI

“(...) Depende da disciplina, do perfil do aluno. Tento abordar os assuntos de modo mais simples, mais contextualizado, com mais atividades de em sala de aula etc. (...)" - P3

\section{“(...) Costumava utilizar o método tradicional quando as aulas eram ministradas presencialmente. A tendência que isto mude. (...)” - P4}

Com base nas informações, a maneira de ensinar Química no Campus Maracanaú é característico de cada professor. Os docentes P1 e P3 informa que depende da disciplina, visto que contextualizam os conteúdos utilizando meios digitais e estratégias de ensino diferentes. No entanto, $\mathrm{P} 4$ parece preferir o método tradicional para ministrar suas aulas. Assim como a forma de ensinar, os problemas enfrentados e as possíveis resoluções também são específicos dos docentes.

As dificuldades e as soluções citadas pelos participantes para o exercício da docência estão representadas na Tabela 2 .

Os professores apresentam dificuldades semelhantes, exceto P3. A compreensão e a maneira de disseminar os conteúdos são os maiores problemas para os docentes, de acordo com o grupo examinado. Diante das respostas para as situações adversas, os participantes também deram soluções aos seus próprios obstáculos. As resoluções exibidas são distintas, embora o problema seja praticamente o mesmo. Logo, podemos deduzir que cada docente, independentemente de sua formação acadêmica inicial, procede conforme suas habilidades pessoais e do jeito que mais apetece a fim de solucionar o problema.

\section{CONSIDERAÇÕES FINAIS}

A pesquisa procurou compreender a pluralidade dos saberes dos professores das específicas da Licenciatura em Química do IFCE - Campus Maracanaú, analisando e comparando os conhecimentos dos participantes.

Percebeu-se através das análises e discussões dos resultados que a pertença dos saberes docentes, principalmente os práticos, independe da formação acadêmica inicial, já que derivam da autonomia dos professores a partir das constantes experiências no mundo acadêmico.

Entretanto, baseado nas respostas dos participantes nos questionários, é perceptível algumas dificuldades no entendimento da temática por parte de determinados docentes, visto que a qualificação profissional interfere nesse quesito.

Constatou-se assim como os saberes, as dificuldades enfrentadas e as soluções são de caráter pessoal, em razão da manifestação dos traços de sua personalidade. Portanto, na medida em que a técnica é empregada, 
A PLURALIDADE DOS SABERES DOS DOCENTES E AS RELAÇÕES ENTRE SI: UMA ABORDAGEM SOBRE A FORMAÇÃO DOS PROFESSORES DA LICENCIATURA EM QUÍMICA NO IFCE MARACANAÚ (CE)

Tabela 2: AS DIFICULDADES E SOLUÇÕES

\begin{tabular}{|c|l|l|}
\hline DOCENTE & \multicolumn{1}{|c|}{ DIFICULDADES } & \multicolumn{1}{|c|}{ SOLUÇÕ̃ES } \\
\hline P1 & Compreender e aproximar os conteúdos à realidade discente & Interação com os alunos \\
\hline P2 & Compreensão dos conteúdos pelos alunos & Diálogo com a turma \\
\hline P3 & Limitações pessoais & Reciclagem pedagógica \\
\hline P4 & $\begin{array}{l}\text { Transmitir os conteúdos aos alunos sem base e manter } \\
\text { a atenção dos alunos }\end{array}$ & Revisão dos conteúdos de base \\
\hline
\end{tabular}

torna-se evidente que os conhecimentos e as competências exercem influência na prática e contribuem com o processo identitário de cada docente.

\section{REFERÊNCIAS}

BOUTIN, A. C. B. D.; SILVA, K. R. d. As reformas educacionais na era vargas e a distinção entre o trabalho manual e intelectual. In: XII Congresso Nacional de Educação. Paraná: PUCPR. Paraná: EDUCERE, 2015. p. 1-12.

BRASIL. Lei no 4127, de 25 de fevereiro de 1942.

Brasilia: Lei no 4127, 1942. Disponível em: <https: //www2.camara.leg.br/legin/fed/declei/1940-1949/ decreto-lei-4127-25-fevereiro-1942-414123। -publicacaooriginal-1-pe.html> Acesso em: 09 jul. 2021.

Lei $n^{0}$ 6545, de 30 junho de 1978.

Brasilia: Lei $n^{\circ} 6545,1978$. Disponível em: <http: //www.planalto.gov.br/ccivil_03/LEIS/L6545.htm> Acesso em: 09 jul. 2021.

Lei $\mathrm{n}^{\circ}$ 11892, de 29 de dezembro de 2008. Brasilia: Lei $\mathrm{n}^{\circ} 11892,2008$. Disponível em: $<$ http://www.planalto.gov.br/ccivil_03/_ato2007-2010/ 2008/lei/l11892.htm> Acesso em: 09 jul. 2021.

CARDOSO, A. A.; PINO, M. A. B. D.; DORNELES, C. L. Os saberes profissionais dos professores na perspectiva de tardif e gauthier: contribuições para o campo de pesquisa sobre os saberes docentes no brasil. In: Seminário de pesquisa em educação da Região Sul. Rio Grande do Sul: IX ANPED Sul, 2012.

COSTA, B. S. Influência da formação pedagógica na prática do docente de EPT. Dissertação (Mestrado em Políticas Públicas e Gestão da Educação Profissional) — Faculdade de Educação, Universidade de Brasília, Brasília, 2013. 103 p.

GARCIA, A. B.; CALDAS, M. H.; PEREIRA, E. O desporto como paradigma: Um problema da educação física escolar? In: II Colóquio de Instituições
Escolares. São Paulo: II Colóquio sobre Pesquisa de Instituições Escolares, 2005.

GAUTHIER, C. Por uma teoria da pedagogia: pesquisas contemporâneas sobre o saber docente. 1 . ed. Rio Grande do Sul: Editora: Unijuí, 2013.

GIL, A. C. Métodos e Técnicas de Pesquisa Social. 7. ed. Ribeirão Preto: Atlas, 2019.

LüDKE, M.; ANDRé, M. E. D. A. Pesquisa em educação: abordagens qualitativas. 2. ed. São Paulo: EPU, 2013.

OLIVEIRA, C. B. d.; SOUZA, A. M. d. C.; OLIVEIRA, M. L. G. d.; LIMA, M. A. M. A influência da pedagogia tecnicista no ambiente organizacional: um estudo do discurso dos egressos do curso técnico. In: Encontro Internacional de Jovens Investigadores. Campina Grande: Realize Editora, 2017. p. $1-10$.

PAULILO, M. A. S. A pesquisa qualitativa e a história de vida. Serviço social em revista, v. 2, n. 2, p. 135-148, 1999.

SAVIANI, D. Escola e Democracia. 44. ed. Campinas: Autores Associados, 2021.

SILVA, A. G. Tendências pedagógicas: perspectivas históricas e reflexões para a educação brasileira.

Unoesc \& Ciência-ACHS, v. 9, n. 1, p. 97-106, 2018.

TARDIF, M. Saberes docentes e formação profissional. 17. ed. Petrópolis: Editora Vozes Limitada, 2014. 